\title{
Farm-scale minimum temperature mapping for strategic and tactical frost management
}

\author{
$\underline{\text { D.L. Gobbett }}^{\text {a }}$, U. Nidumolu ${ }^{\text {a }}$, H. Jin ${ }^{\text {b }}$, J. Gallant ${ }^{\text {c }}$, G. Hopwood ${ }^{\text {a }}$, S. Crimp ${ }^{\text {a }}$ \\ ${ }^{a}$ CSIRO Agriculture and Food; ${ }^{b}$ CSIRO Data61; ${ }^{c}$ CSIRO Land and Water \\ Email: david.gobbett@,csiro.au
}

\begin{abstract}
Frost causes millions of dollars of damage to broad acre cereal crops and is an important climate risk that presents a management challenge to grain growers in Australia. Management options to mitigate impact of frost include pre-season cropping decisions such as timing of sowing, choice of crop type and cultivar, and post-frost event management such as cutting for hay, or grazing frost-damaged crops. This study, conducted in close collaboration with growers and farm consultants, contributes to both pre-season and postfrost management through improved spatio-temporal understanding of frost risk.
\end{abstract}

This study aims to identify combinations of meteorological and terrain variables suitable for generating high spatial resolution (approx. $30 \mathrm{~m}$ ) maps of minimum temperature $\left(\mathrm{T}_{\min }\right)$. This mapping used Multivariate Adaptive Regression Splines (MARS) models to combine terrain indices with temperature data. Modelling and mapping were undertaken for two sites in the SE Australian cereal-cropping zone, Mintaro, South Australia and Hopetoun, Victoria. To facilitate the development of the mapping methodology, iButton ${ }^{\circledR}$ temperature loggers were deployed at each site during June-September 2016. A clustering-based sampling scheme, for 96 loggers at each site, sought to capture terrain-driven temperature variability at landscape scale $(4 \times 4 \mathrm{~km}$ at the Mintaro site; 5 x $3 \mathrm{~km}$ at the Hopetoun site). The logger dataset from the Mintaro site included data from 71 loggers over 25 cold nights $\left(<2^{\circ} \mathrm{C}\right)$ and from the Hopetoun site 87 loggers over 20 cold nights, with temperatures recorded at 30 minute intervals.

MARS models were developed to predict the logger $\mathrm{T}_{\min }$ values. We compared models using three separate sources of temperature data, a local weather station at each site, an official weather station and remotely sensed Moderate Resolution Imaging Spectroradiometer (MODIS) night-time land surface temperatures. We also developed models using temperature loggers themselves as predictors for the entire site, both individually, and with all 3-logger combinations for each site.

Comparing models which used local, distant, and remotely sensed temperature predictors showed that locally measured temperatures generate the best models. Then, using the individual loggers as predictors showed that wind speed and humidity were important predictors in many cases. Additionally, by modelling every threelogger combination for each site, we demonstrated that some logger locations were not used in any models, and further, some models using a single logger performed well.

There are several practical findings from this work. Firstly, local temperature measurements show the best potential for generating high-resolution maps of $\mathrm{T}_{\min }$ at farm scale. Our results also suggest that remotely sensed temperature is not acquired reliably enough to make it suitable for this purpose. Models based on temperature data from one to three logger locations fitted well, but showed that location of loggers may be important. The improvement to models by including wind-speed and humidity measurements shows that these may be important parameters to measure. With further validation and refinement of the methods, we believe this method has the potential to be applied across the broad acre cropping areas of Australia.

Keywords: Minimum temperature, terrain, Multivariate Adaptive Regression Splines (MARS), Moderate Resolution Imaging Spectroradiometer (MODIS) 


\section{INTRODUCTION}

Frost damage to cereal crops through reduced yields and damage to grain is estimated at between $\$ 120$ and $\$ 700$ million per annum in Australia (see Crimp et al. 2016). Frost can occur as severe and catastrophic events, and trends observed in some areas of south-eastern Australia show increased frost season lengths affecting cereal growers (Crimp et al. 2016). Many factors influence susceptibility of crops to damage including crop variety, phenological stage and degree of acclimatization. At a farm scale, minimum air temperatures vary spatially and may be affected by terrain position, localised air movements, soil moisture, crop biomass and stubble ground cover. Growers make strategic frost management decisions at a farm scale, such as selecting crop variety for frost hardiness and sowing times which affect time of flowering, a vulnerable cereal crop stage. Tactical decisions are also made after frost events to maximize the value of damaged crops, for example by cutting for hay.

Radiative frost, the most common type of frost in broad acre cropping areas, does not occur uniformly across the landscape. Farmers might rely on a single weather station many kilometres away for frost information, and very limited spatial data are available at a resolution suited for farm decision making. Thus a key problem in managing frost over a whole farm is that temperatures recorded at a single weather station do not indicate the temperature a crop is exposed to (De Melo-Abreu et al. 2016). To facilitate better pre-sowing management decisions and better target tactical responses after frost events, growers would benefit from higher resolution maps of minimum temperatures $\left(\mathrm{T}_{\min }\right)$.

This study investigates the potential to use MARS modelling to integrate a range of meteorological, remotely sensed and terrain data to derive high-resolution maps of $\mathrm{T}_{\min }$ suitable for farm decision support. A number of previous studies have produced high-resolution maps of climatic variables by combining spatial predictors (derived from digital elevation models) with temperature data, using statistical modelling methods (e.g. Aalto et al. 2017; Ashcroft and Gollan 2012; Webb et al. 2016). Other studies have used remotely sensed temperatures, such as Moderate Resolution Imaging Spectroradiometer (MODIS) Land Surface Temperature (LST) product for frost and $\mathrm{T}_{\min }$ mapping (Gobbett et al. in press; Simoes et al. 2015) (remotely sensed temperature is anticipated to be suitable because frosts in the Australian broad-acre cropping areas are mainly radiative frosts, occurring on clear cloud free nights). However, such studies do not provide the spatial or temporal resolutions to address grain growers' need for improved temperature mapping at farm scale, with daily frequency. We compare the utility of temperature measurements locally, and from more distant weather station data and remote sensing. Through this we develop some preliminary practical recommendations for farm scale temperature mapping.

\section{METHODS}

The central methodology used in this study was the application of Multivariate Adaptive Regression Splines (MARS; Friedman 1991) models to amalgamate terrain indices with temperature data. Models were developed to enable the prediction of minimum temperature across a landscape at the scale of the terrain indices (approx. $30 \mathrm{~m}$ pixels). To acquire data to enable the development of suitable models, temperature loggers were deployed during winter 2016, capturing temperature data over the range of terrain variation at each site.

\subsection{Study sites}

Two study sites (Figure 1) were chosen on the basis of (a) a history of frost damage, (b) terrain (an elevation range of at least $20 \mathrm{~m}$, a topography including at least one gully where air flow might converge and (c) land use representative of farmland in the broader region.

(a)

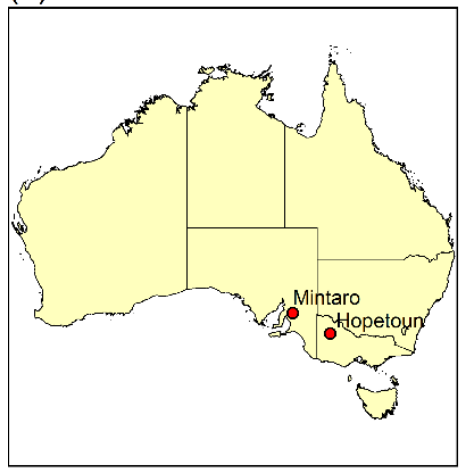

(b)

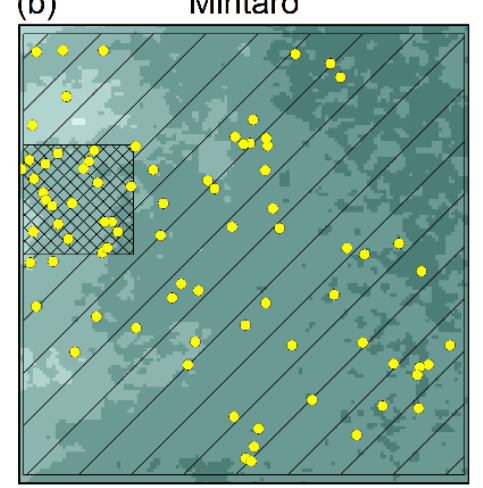

(c)

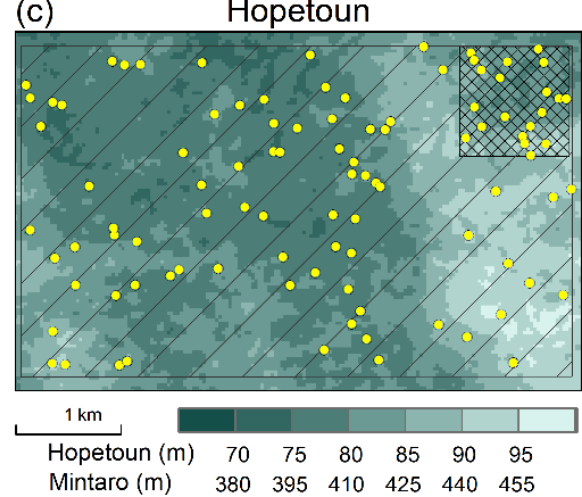

Figure 1. (a) Location of sites and deployed iButton ${ }^{\circledR}$ logger locations, overlaid on terrain elevation for (b) Mintaro site $(4 \times 4 \mathrm{~km})$ and (c) Hopetoun site $(5 \times 3 \mathrm{~km})$. Cross-hatched areas are the high density logger sampling areas. 
Both sites included access to an in situ weather station to capture temperature and wind speed at sub-hourly frequency, as well as an Australian Bureau of Meteorology (BoM) weather station within $20 \mathrm{~km}$. The Mintaro site (Figure 1b) of $4 \times 4 \mathrm{~km}$ comprises a higher elevation in the western section with valleys running to the east into the site and a much flatter area across the eastern half of the site. The Hopetoun site (Figure 1c) of 5 x $3 \mathrm{~km}$ is in typical Mallee dune-swale landscape with higher dunes at the western and eastern ends of the site running NNE to SSW, and a large swale between, containing some undulations.

\subsection{Terrain variables}

Terrain is an important contributor to patterns of $\mathrm{T}_{\min }$. A variety of topographic indices have been utilized in studies modelling cold air temperatures (e.g. see Aalto et al. 2017; Webb et al. 2016). Terrain variables were derived from the national 1 arc second (approx. $30 \mathrm{~m}$ pixel) Shuttle Radar Topography Mission (SRTM) derived elevation model (DEM; Gallant et al. 2011). To stratify the location of loggers in this study (see below), we preselected several DEM derived variables for their anticipated usefulness in characterizing terrain influences on cold air movement, soil moisture and diurnal solar warming of the surface (Table 1). In the MARS modelling process (described below), we utilized additional elevation residual indices (radii of 100, 320, $1,000,3,000$ and 10,000 m) and elevation range datasets (radii of 50, 70, 100, 140, 200,320, 500, 700, 1,000 and 1,400 m). Multi-resolution Valley Bottom Flatness index (MrVBF) was excluded from MARS modelling due to the composite nature of the index, and elevation due to it being a relative rather than absolute value.

Table 1. Terrain indices selected for logger sampling scheme and temperature modelling. Variables are listed in descending order of (a priori) expected influence on temperatures.

\begin{tabular}{|l|l|}
\hline \multicolumn{1}{|c|}{ Variable } & \multicolumn{1}{c|}{ Description } \\
\hline Elev residual $320 \mathrm{~m}$ & Elevation minus the mean elevation within a radius (i.e. relative position in the terrain) \\
\hline Elev range 320m & Range of elevation within a radius (i.e. 'terrain complexity' around a point) \\
\hline MrVBF & Multi-resolution Index of Valley Bottom Flatness. (Gallant and Dowling 2003) \\
\hline Elevation & Elevation above datum \\
\hline SWSRR_June & June short wave solar radiation ratio. Incorporates slope, aspect (Gallant et al. 2014) \\
\hline TWI & DEM derived topographic wetness index (Gallant and Wilson 2000) \\
\hline
\end{tabular}

\subsection{Temperature logger deployments}

To obtain data with which to model minimum temperatures across the landscapes, 96 iButton ${ }^{\circledR}$ temperature loggers (DS1922L; Maxim Integrated Products, California) were used to capture temperature data at each of the two study sites (Figure 1). To design the sampling scheme, terrain variables (Table 1) were used with clustering techniques (e.g. Jin et al. 2005) to ensure the loggers were distributed across the terrain variability as represented by the chosen variables. Since MODIS downscaling was a key focus, the sampling scheme included an area of high density loggers i.e. 20 loggers corresponding to one MODIS pixel $\left(1 \mathrm{~km}^{2}\right)$, intended to capture within-pixel temperature variation. The remaining area containing at least one logger per $1 \mathrm{~km}^{2}$. To avoid obstructing farm operations such as crop spraying, the loggers were deployed at $50 \mathrm{~cm}$ above the ground. The iButtons were supported by wire stakes, constructed from high tensile fencing grade wire, which included an arm providing a $12 \mathrm{~cm}$ offset from the stake. Each logger was configured to log temperature at high resolution $\left(0.0625^{\circ} \mathrm{C}\right)$ at 30 minute intervals. Logger data were cleaned to remove anomalous data and were then splined using cubic spline interpolation (R Core Team 2017) to generate temperature readings at 1 minute intervals. Nightly logger $T_{\min }$ was derived from the 1 minute splined data.

\subsection{Weather variables for modelling}

Temperature and weather variables from three sources were used in the Tmin modelling. (a) A meteorological station at each study site recording overnight Tmin $\left({ }^{\circ} \mathrm{C}\right)$, wind speed $(\mathrm{m} / \mathrm{s})$ and average humidity $(\%) ;(b)$ Overnight $\mathrm{T}_{\min }$ from the nearest official Bureau of Meteorology (BoM) stations, at Hopetoun $15 \mathrm{~km} \mathrm{E}$ of the study site (Hopetoun Airport, BoM station: 77010) and at Mintaro $16 \mathrm{~km} \mathrm{WNW}$ of the study site (Clare High School, BoM station: 21131); (c) MODIS (Aqua) satellite Land Surface Temperature (LST) product MYD11A1 (v5; Wan 2008) preprocessed for the Australian region (Paget and King 2008) with a spatial resolution of $1 \mathrm{~km}^{2}$. Over the dates of the temperature logger deployments, the mean MODIS overpass (in local time) was 1:37 am at Hopetoun and 1:56 am at Mintaro. MODIS LST values were spatially extracted from stacked MODIS data for each of the logger locations using the R raster 'extract' function (Hijmans 2016).

\section{Multivariate Adaptive Regression Splines modelling}

MARS is a nonparametric regression procedure which extends linear modelling through the use of hinge functions, and also accommodates interactions between variables. MARS methods have been successfully applied to related areas such as downscaling satellite derived thermal imagery utilising terrain variables (Qi et 
al. 2016), and in modelling daily $\mathrm{T}_{\min }$ in the Yarra Valley, Victoria (Gobbett et al. in press). Here we use the 'earth' implementation of MARS methods (Milborrow 2017), within the R environment (R Core Team 2017).

Earth models, with the logger $\mathrm{T}_{\min }$ as the dependent variable, were generated individually for Hopetoun and Mintaro, and also using combined data from both sites. To restrict the dataset to potential frost nights, nights were only included in modelling if the local met station $\mathrm{T}_{\min }$ was $<2{ }^{\circ} \mathrm{C}$. Models separately used the three sources of temperature predictors, including local weather station, BoM station and MODIS predictors. Local average wind speed and humidity from the local weather station were also used in combination with local $\mathrm{T}_{\min }$. The same terrain variables outlined above were included as predictors in all models. Day of the year (DOY) was also included as a predictor. The following 'earth' parameters were used consistently to allow comparison among models: degree $=2$ (maximum degree of interaction between predictors); nprune $=8$ (setting the maximum number of MARS terms). The nprune term was determined after some trial and error, and this value was found to be a compromise between model simplicity while maintaining a good $\mathrm{R}^{2}$, and importantly, ensuring that most models included a spatial terrain parameter. Model performance was evaluated using $\mathrm{R}^{2}$, RMSE and cross-validation $\mathrm{R}^{2}\left(\mathrm{CV} \mathrm{R}^{2}\right)$. Cross validations of the earth models were performed using nfold = 10 , ncross $=10$ (performing 10 cross-validations using 10 cross-validation folds), except in the case of the 3 logger combination models, where for performance reasons, the cross-validation used nfold $=5$, ncross $=5$. For selected earth models and nights, the earth 'predict' function was used to apply the MARS models to generate minimum temperature surfaces at the resolution (approx. 30m) of the terrain datasets.

To examine temperatures measured at different locations within the study sites, MARS models were generated in which all the combinations of 3 loggers at each site were used as temperature predictors for the remaining $\operatorname{logger} \mathrm{T}_{\text {mins }}$. To enable this we prepared a cross tabulated dataset of logger $T_{\min }$ data that was filtered to remove any nights where data from more than 20 loggers were missing for each night, and then further filtered to remove any remaining loggers for which had missing readings.

\section{RESULTS}

\subsection{Logger data}

At the Mintaro site, loggers were deployed for 69 days ( $16^{\text {th }}$ June to $22^{\text {nd }}$ August 2016), while Hopetoun loggers were deployed for 85 days ( $28^{\text {th }}$ June to $21^{\text {st }}$ September 2016), although farm operations prevented deployment in a few paddocks until $21^{\text {st }}$ July 2016. The subset of logger data selected for MARS modelling, only included nights where the local weather station $\mathrm{T}_{\min }$ fell below $2^{\circ} \mathrm{C}$. The resulting Mintaro dataset included data from 71 loggers over 25 cold nights (1544 separate logger $\mathrm{T}_{\min }$ values) and the Hopetoun dataset included data from 87 loggers over 20 cold nights (1581 separate logger $\mathrm{T}_{\min }$ values).

\subsection{Local, distant and remotely sensed temperature}

We compared the MARS models predicting the logger $\mathrm{T}_{\min }$, where each model used only one temperature data source, (a) local weather station $\mathrm{T}_{\min }$ (Local $\mathrm{T}_{\min }$ ) either with or without associated average wind speed, (b) the 15-16 km distant BoM station (BoM $\mathrm{T}_{\min }$ ), and (c) MODIS LST. Mintaro and Hopetoun sites were modelled separately, as well as models using a combined dataset. Table 2 summarises the predictors selected in those models, including predictor importance from the evimp tool (Milborrow 2017). Figure 2 shows MARS model $\mathrm{T}_{\min }$ predictions for 15th August 2016, when severe frost affected both Mintaro (top) and Hopetoun (bottom).

The models using the local weather station data resulted in better models than either the BoM station or MODIS LST at both Mintaro and at Hopetoun. One exception was Hopetoun, where the Local $\mathrm{T}_{\min }$ (without wind speed) model and MODIS LST model performed comparably well. The best models produced were for Mintaro using Local $\mathrm{T}_{\min }$ with $\left(\mathrm{CV} \mathrm{R}^{2}=0.82\right)$. DOY showed up as a more important predictor in models with MODIS LST than with the other temperature predictor variables. Wind was not included by MARS in models for Mintaro, but was included for Hopetoun (perhaps due to flatter terrain) as well as the combined model. Humidity was not selected in any of the models, further investigation is required as to the reasons for this.

Of the terrain variables selected in the MARS models, 3000 m radius Elevation Residual was moderately to highly important in all models, except the Mintaro MODIS LST model which incorporated the $1000 \mathrm{~m}$ radius elevation residual instead. Elevation range was less consistent as a predictor, with the importance being equal or lower than elevation residual in all models. Elevation range over $1000 \mathrm{~m}$ was most used in Hopetoun models, and elevation range over $320 \mathrm{~m}$ was most used in Mintaro models. Elevation range was not included in any models that used the more distant BoM station $\mathrm{T}_{\min }$ data. June short wave radiation ratio was only included in one model, the MODIS LST model for Mintaro.

A key finding with MODIS LST data was that, due to unsuitable atmospheric conditions, LST coverage was unavailable at both sites on $30 \%$ of the nights where frost occurred (i.e. local weather station $\mathrm{T}_{\min }<2^{\circ} \mathrm{C}$ ). 
Gobbett et al., Farm-scale minimum temperature mapping for strategic and tactical frost management

Table 2. Summary of earth models predicting logger $\mathrm{T}_{\min }$ using temperature predictors from local met station, BoM station and MODIS LST, showing predictor importance (output by MARS evimp function) and model errors. Shading of $\mathrm{R}^{2}, \mathrm{CV} \mathrm{R}{ }^{2}$ and RMSE columns show better performing models with darker shades.

\begin{tabular}{|c|c|c|c|c|c|c|c|c|c|c|c|c|c|c|}
\hline \multirow[b]{2}{*}{ Site } & \multirow[b]{2}{*}{$\begin{array}{l}\text { Temperature } \\
\text { predictor }\end{array}$} & \multicolumn{10}{|c|}{ Predictor importance } & \multirow[b]{2}{*}{ 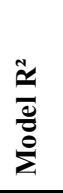 } & \multirow[b]{2}{*}{$\stackrel{\pi}{\simeq}$} & \multirow[b]{2}{*}{$\sum_{\simeq}^{5}$} \\
\hline & & 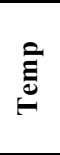 & 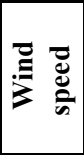 & ठ̀ & 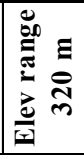 & 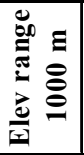 & 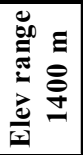 & 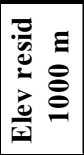 & 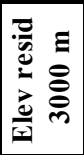 & 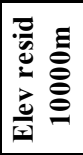 & 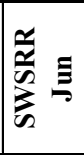 & & & \\
\hline \multirow[t]{4}{*}{ Hopetoun } & Local $T_{\min }$ & 74 & & 24 & & 34 & & & 100 & & & 0.68 & 0.74 & 0.91 \\
\hline & Local $T_{\min }(+$ Wind $)$ & 75 & 32 & 32 & & 32 & & & 100 & 9 & & 0.70 & 0.76 & 0.88 \\
\hline & BoM $\mathrm{T}_{\min }$ & 73 & & 30 & & & & 16 & 100 & & & 0.66 & 0.75 & 0.94 \\
\hline & MODIS LST & 68 & & 48 & & 20 & & & 100 & & & 0.68 & 0.72 & 0.91 \\
\hline \multirow[t]{4}{*}{ Mintaro } & Local Tmin & 100 & & 17 & 23 & & 5 & 5 & 48 & & & 0.76 & 0.82 & 0.74 \\
\hline & Local $T_{\min }(+\mathrm{W}$ ind $)$ & 100 & & 17 & 23 & & 5 & 5 & 48 & & & 0.76 & 0.82 & 0.74 \\
\hline & BoM Tmin & 100 & & 56 & & & & & 67 & & & 0.69 & 0.79 & 0.85 \\
\hline & MODIS LST & 100 & & 82 & 39 & & & 39 & & & 21 & 0.69 & 0.77 & 0.91 \\
\hline \multirow[t]{4}{*}{ Combined } & Local Tmin & 100 & & 11 & & 16 & 31 & 21 & 58 & 24 & & 0.68 & 0.74 & 0.90 \\
\hline & Local $T_{\min }(+$ Wind) & 100 & 33 & 26 & & 21 & & & 59 & & & 0.69 & 0.75 & 0.89 \\
\hline & BoM Tmin & 82 & & 38 & & & & 26 & 100 & & & 0.59 & 0.71 & 1.01 \\
\hline & MODIS LST & 74 & & 62 & & & & 22 & 100 & & & 0.54 & 0.60 & 1.11 \\
\hline
\end{tabular}

(a)

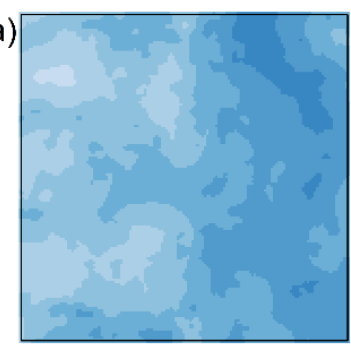

(d)

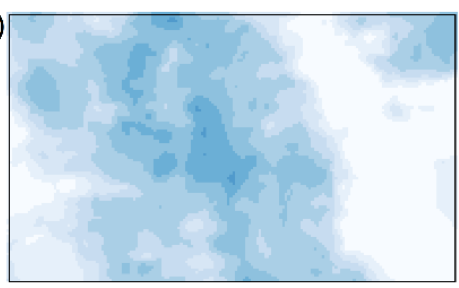

Minimum temperature $\left({ }^{\circ} \mathrm{C}\right)$

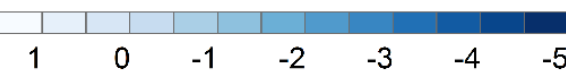

(b)

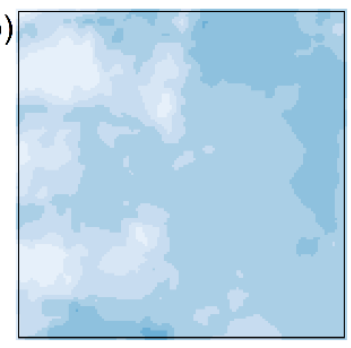

(e)

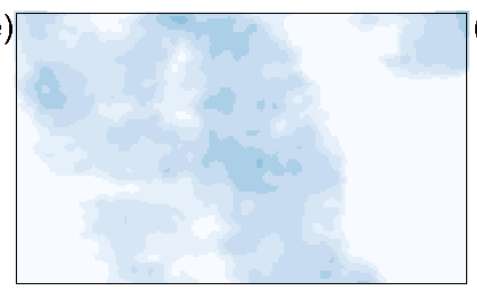

$-5$ (c)
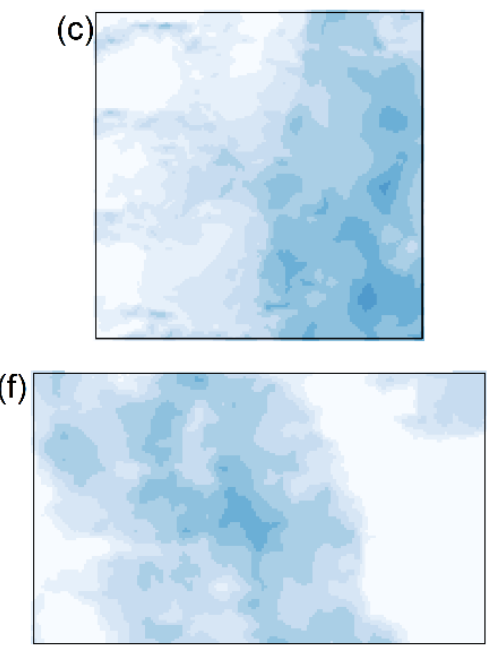

0 $1 \mathrm{~km}$

Figure 2. Examples of MARS model $T_{\min }$ predictions for $15^{\text {th }}$ August 2016, when severe frost affected both Mintaro (top) and Hopetoun (bottom). (a, d) predictions using local weather station $\mathrm{T}_{\min }$ and terrain indices $(\mathrm{b}, \mathrm{e})$ predictions using

BoM station $T_{\min }$ and terrain indices, (c, f) predictions using MODIS LST data (approx. $1 \mathrm{~km}^{2}$ ) and terrain indices.

\subsection{Individual logger models}

MARS models were generated using each individual logger $T_{\min }$ as a predictor for the remaining loggers. While humidity was not used in the preceding models using Local $\mathrm{T}_{\min }$, BoM $\mathrm{T}_{\min }$ or MODIS LST, it is interesting that it was used in almost half of all models using loggers as the $\mathrm{T}_{\min }$ predictor at both sites, and had similar importance as wind speed at both sites (results not shown). To investigate whether wind speed and humidity variables are important at particular locations in the terrain, we mapped the importance of wind speed and humidity for the loggers across both sites. However this showed no correlation with terrain variables or landscape position (results not shown), so may require further investigation.

\subsection{Multiple logger models}

By generating MARS models using all possible 3-logger combinations as temperature predictors for each site, we investigated whether any combination of loggers provided substantially improved models, and combinations of 1, 2 or 3 loggers performed substantially differently overall, and further, whether any locations were more or less important across the sites. After removing loggers which did not capture data over all nights, $\mathrm{T}_{\min }$ data were available from 74 loggers over 15 cold nights at the Hopetoun site and 46 loggers over 25 cold nights at the Mintaro site. Of 15180 models fitted for the Mintaro site, 11\% used only one of three loggers, $60 \%$ used two and the remaining 29\% used all three loggers (Table 3). That some 1 logger models 
outperformed 2 and 3 logger models suggests that additional loggers would provide limited improvement to modelled minimum temperatures provided they are optimally located. Further, 25 of the Mintaro loggers were not selected by MARS in any of the models. Similar results were obtained from 64,824 models fitted for the Hopetoun site (results not shown). This demonstrates that some locations are less useful for farm scale minimum temperature predictions, and that location of loggers may be important.

Table 3. Summary of Mintaro models in which 15180 combinations of three loggers were used as temperature predictors for the entire site.

\begin{tabular}{|l|l|l|l|l|}
\hline Loggers in model & Proportion & mean $\mathbf{R}^{\mathbf{2}}$ & mean CV $\mathbf{R}^{\mathbf{2}}$ & mean RMSE \\
\hline 1 & $11 \%$ & 0.779 & 0.839 & 0.718 \\
\hline 2 & $60 \%$ & 0.772 & 0.839 & 0.729 \\
\hline 3 & $29 \%$ & 0.773 & 0.839 & 0.728 \\
\hline
\end{tabular}

\section{DISCUSSION AND CONCLUSIONS}

We have successfully utilized a variety of temperature data sources and terrain indices to generate highresolution maps of minimum temperature. For optimal tactical decision making in response to frost, farmers need to know, in a timely manner, where in their paddocks frosts have been most severe. This will help them to inspect crops for damage, and make prompt decisions if crops are to be cut for hay instead of allowed to grow to maturity for harvest.

We have identified key terrain variables relevant to $\mathrm{T}_{\min }$ modelling at each site, and shown the elevation residual with $3 \mathrm{~km}$ radius to be the most important predictor, usually in combination with an elevation range variable. Generally, and unsurprisingly, more local temperature measurements were better predictors than distant stations and remotely sensed data. For both sites, local temperature measurements produced the best-fitted models, and MODIS LST performed similarly to, or less well than a single BoM station many kilometres from the study sites. However, given our assumption that frosts in our broad acre cropping study regions are radiative frosts, we were surprised that MODIS nightly coverage was not available for about $30 \%$ of nights at both sites. This demonstrates a key limitation of remote sensing for daily high resolution $T_{\text {min }}$ mapping, which ideally needs to be available immediately following a frost event to assist farmers in damage assessment and tactical response to a frost event. Furthermore, our results confirm that one to three local temperature and wind measurements can be used to generate robust high resolution $\mathrm{T}_{\min }$ maps.

Daily $\mathrm{T}_{\min }$ maps (and similar models of duration of low temperatures, results not shown) can be used by farmers to aid in assessment of crop damage following a frost event, and therefore can contribute to improving tactical response. Furthermore, these maps can be aggregated over one or more cropping seasons to highlight areas most at risk of frost, and therefore contribute to strategic management of frost risk, such as in selection of crop variety and sowing dates.

Two key practical findings were derived from using loggers as $\mathrm{T}_{\min }$ inputs into MARS models. First, the single logger modelling showed, despite earlier results, that wind speed and humidity may be important to measure. The lack of spatial pattern in where wind and humidity were included in models suggests this needs to be further tested. Secondly, models generated using 3-logger combinations showed that one logger can result in models as well fitted as some with three loggers. This, together with the finding that some loggers were not used in any of the models, highlights that the location of loggers within the site is important; an aspect which clearly should be further investigated.

The importance of the DOY predictor in the MARS models is an area for further investigation, since this nonphysical variable may be reflecting a number of non-measured factors such as soil temperature (perhaps declines over the season), incident solar radiation, crop biomass or height effects. In the case of MODIS models, this may also be capturing the change in elapsed time between MODIS overpass (around 1:30 am) and the time of $\mathrm{T}_{\min }$ which usually occurs closer to dawn.

\subsection{Conclusions}

This work has demonstrated that local temperature measurements show the best potential for generating highresolution maps of minimum temperature at farm scale. The addition of wind-speed and humidity measurements also improves models. With further validation and refinement of the methods, we believe this method has the potential to be applied across broad acre cropping areas of Australia. The results suggest that remotely sensed temperature is not acquired reliably-enough to make that suitable for this purpose.

Further work should focus on utilizing terrain indices to contribute to optimizing the location of the local weather station(s). Also the selection of different terrain indices in MARS models for the two study sites suggests the possible value of devising a topographic typology of landscapes in relation to patterns of minimum 
temperatures. Using only one to three loggers for a farm area (a few square $\mathrm{km}$ ) appears to be adequate for farm scale mapping, but further work should contribute to quantifying model accuracy and developing recommendations for sensor placement locations. In addition, for further scaling-up to cover broad-acre cropping areas nationally, additional modelling should include proximity to coast and water bodies.

\section{ACKNOWLEDGEMENTS}

This project was funded by the Grains Research and Development Corporation (GRDC) project CSP00198. Field and logistics assistance was provided by Kelly Angel (Birchip Cropping Group) at Hopetoun and Mick Faulkner and Jana Dixon at Mintaro. Mintaro weather station data were provided by Michael Zerner, (University of Adelaide). We appreciate the cooperation of farmers at both sites.

\section{REFERENCES}

Aalto, J., Riihimäki, H., Meineri, E., Hylander, K., \& Luoto, M. (2017). Revealing topoclimatic heterogeneity using meteorological station data. International Journal of Climatology. DOI: 10.1002/joc.5020

Ashcroft, M.B., \& Gollan, J.R. (2012). Fine-resolution $(25 \mathrm{~m})$ topoclimatic grids of near-surface $(5 \mathrm{~cm})$ extreme temperatures and humidities across various habitats in a large $(200 \times 300 \mathrm{~km})$ and diverse region. International Journal of Climatology 32: 2134-2148

Crimp, S.J., Zheng, B., Khimashia, N., Gobbett, D.L., Chapman, S., Howden, M., \& Nicholls, N. (2016). Recent changes in southern Australian frost occurrence: implications for wheat production risk. Crop and Pasture Science, 67, 801

De Melo-Abreu, J.P., Villalobos, F.J., \& Mateos, L. (2016). Frost Protection. In F.J. Villalobos, \& E. Fereres (Eds.), Principles of Agronomy for Sustainable Agriculture (pp. 443-457). Springer International Publishing

Friedman, J.H. (1991). Multivariate Adaptive Regression Splines. The Annals of Statistics, 19, 1-67

Gallant, J., Austin, J., \& Van Niel, T. (2014). Mean monthly shortwave radiation ratio modelled using the 1" DEM-S. v2. http://doi.org/10.4225/08/53D08D89BFCB1.

Gallant, J.C., \& Dowling, T.I. (2003). A multiresolution index of valley bottom flatness for mapping depositional areas. Water Resources Research, 39, 1347

Gallant, J.C., Dowling, T.I., Read, A.M., Wilson, N., Tickle, P., \& Inskeep, C. (2011). 1 second SRTM Derived Digital Elevation Models User Guide. Geoscience Australia

Gallant, J.C., \& Wilson, J.P. (2000). Primary Topographic Attributes. In J.P. Wilson, \& J.C. Gallant (Eds.), Terrain Analysis: Principles and Applications (pp. 51-85). New York: John Wiley and Sons

Gobbett, D.L., Nidumolu, U., \& Crimp, S. (in press). Modelling frost generates insights for managing risk of minimum temperature extremes. Weather and Climate Extremes

Hijmans, R.J. (2016). raster: Geographic Data Analysis and Modeling. R package version 2.5-8. https://CRAN.R-project.org/package=raster

Jin, H., Leung, K.-S., Wong, M.-L., \& Xu, Z.-B. (2005). Scalable model-based cluster analysis using clustering features. Pattern Recognition, 38, 637-649

Milborrow, S. (2017). earth: Multivariate Adaptive Regression Splines, Derived from mda:mars by Trevor Hastie and Rob Tibshirani. Uses Alan Miller's Fortran utilities with Thomas Lumley's leaps wrapper. https://CRAN.R-project.org/package=earth

Paget, M.J., \& King, E.A. (2008). MODIS Land data sets for the Australian region. In, Internal Report No. 004 (2008) (p. 96pp). Black Mountain, Canberra, Australia: CSIRO Marine and Atmospheric Research

Qi, P., Hu, S., Zhang, H., \& Guo, G. (2016). Sharpening method of satellite thermal image based on the geographical statistical model. Journal of Applied Remote Sensing, 10, 025013

R Core Team (2017). R: A language and environment for statistical computing. R Foundation for Statistical Computing, Vienna, Austria

Simoes, D.D., Fontana, D.C., \& Vicari, M.B. (2015). Use of LST images from MODIS/AQUA sensor as an indication of frost occurrence in RS. Revista Brasileira De Engenharia Agricola E Ambiental, 19, 920-925

Wan, Z. (2008). New refinements and validation of the MODIS Land-Surface Temperature/Emissivity products. Remote Sensing of Environment, 112, 59-74

Webb, M.A., Hall, A., Kidd, D., \& Minansy, B. (2016). Local-scale spatial modelling for interpolating climatic temperature variables to predict agricultural plant suitability. Theoretical and Applied Climatology, 124, 1145-1165 